\title{
Effect of Novel Design Modifications on Fibrotic Encapsulation: An In Vivo Glaucoma Drainage Device Study in a Rabbit Model
}

\author{
Nathan A. Fischer - Malik Y. Kahook - Suhail Abdullah • \\ Eric Porteous - David A. Ammar · Jennifer L. Patnaik · \\ Jeffrey R. SooHoo
}

Received: January 18, 2020 / Published online: March 9, 2020

(C) The Author(s) 2020

\section{ABSTRACT}

Purpose: To quantify the effects of modified Ahmed glaucoma valves ${ }^{\circledR}$ (AGV) with anti-fibrotic plate coatings or a plate surface micropattern on outflow resistance and tissue response.

Methods: Twelve New Zealand rabbits were divided into four groups: commercially available AGV implants $(n=3)$, AGV with hydrophilic coating $(n=3)$, AGV with heparin coating $(n=3)$, and AGV with a plate surface micro-pattern $(n=3)$. After 6 weeks, the anterior chamber silicone tube was cannulated

Enhanced digital features To view enhanced digital features for this article, go to https://doi.org/10.6084/ m9.figshare.11882403.

N. A. Fischer · M. Y. Kahook · J. L. Patnaik ·

J. R. SooHoo $(\bowtie)$

Department of Ophthalmology, University of Colorado School of Medicine, Aurora, CO, USA

e-mail: jeffrey.soohoo@cuanschutz.edu

S. Abdullah · E. Porteous

New World Medical, Inc., Rancho Cucamonga, CA, USA

D. A. Ammar

Lions Eye Institute for Transplant and Research,

Tampa, FL, USA in situ and perfused with $2.5 \mu \mathrm{L} / \mathrm{min}$ of saline. The pressures were recorded with a perfusion system to measure outflow resistance. The rabbits were then euthanized followed by enucleation of all eyes for bleb histological analyses.

Results: Hydrostatic pressures were significantly lower in AGVs with the hydrophilic plate coating (mean difference $-9.6 \mathrm{~mm} \mathrm{Hg}$; $p<0.001$ ), heparin-coated plates (mean difference $-4.4 \mathrm{~mm} \mathrm{Hg} ; p<0.001$ ), and micro-patterned plates (mean difference $-18.6 \mathrm{~mm} \mathrm{Hg}$, $p<0.001$ ), indicating lower outflow resistance compared to control AGV models. Fibrotic encapsulation was lower in hydrophilic plate coating $(84.2 \mu \mathrm{m}$; mean difference $-6.2 \mu \mathrm{m}$, $p=0.425)$, micro-patterned surface $(63.7 \mu \mathrm{m}$; mean difference $-26.7 \mu \mathrm{m}, p=0.003)$, and heparin plate coating $(49.3 \mu \mathrm{m}$; mean difference $-41.1 \mu \mathrm{m}, p=0.006)$ when compared to control AGV models.

Conclusions: Modified AGVs with plate coatings and AGVs with micro-patterned plates both appear to reduce postoperative fibrotic encapsulation and aqueous outflow resistance by altering the tissue response to implanted materials. Further studies are needed to characterize the safety and role of plate surface modifications on glaucoma drainage devices.

Keywords: Ahmed glaucoma valve; Glaucoma drainage device; Post-operative encapsulation; Valve perfusion 


\section{Key Summary Points}

\section{Why carry out this study?}

While the use of glaucoma drainage devices (GDD) has increased in the surgical management of glaucoma, their success is limited by high 5-year failure rates. Studies have shown that fibrotic encapsulation at the implant site is the most common cause of device failure as it results in increased outflow resistance and inadequate control of intraocular pressure.

The purpose of the study was to quantify the effects of modified Ahmed glaucoma valves ${ }^{\circledR}(\mathrm{AGV})$ with anti-fibrotic plate coatings or a plate surface micro-pattern on outflow resistance and histologic tissue response.

\section{What was learned from this study?}

Hydrostatic pressures were significantly lower in all modified AGVs, and fibrotic encapsulation was significantly lower in the heparin plate coating and micropatterned surface when compared to the control.

Modified AGVs with plate coatings as well as AGVs with micro-patterned plates appear to reduce postoperative fibrotic encapsulation and aqueous outflow resistance by altering the tissue response to implanted materials.

\section{INTRODUCTION}

Approximately 60 million people are affected by glaucoma, making it the leading cause of irreversible blindness worldwide [1]. Lowering intraocular pressure (IOP) continues to be the primary target in treating glaucoma. Since the Tube Versus Trabeculectomy Study demonstrated some short- and long-term advantages over trabeculectomy, implantable glaucoma devices have been increasingly used when other nonsurgical treatment modalities have failed. Although the use of glaucoma drainage devices (GDD) has increased, success remains limited as the probability of tube failure at 5 years has been shown to be $31.8 \%$ [2]. Failure of these implants is most commonly caused by fibrotic encapsulation of the shunt at the implant site. Studies have shown fibrotic encapsulation results in increased outflow resistance leading to inadequate control of IOP [3-5].

The use of antimetabolites such as mitomycin C (MMC) and 5-fluorouracil (5-FU) has been shown to improve success rates of trabeculectomy in large clinical trials and decades of clinical practice [6-8]. Unfortunately, multiple studies have shown that use of MMC in GDD implantation does not increase success rates $[9,10]$. Additionally, adverse effects including infection, wound dehiscence, tube extrusion, and persistent fibrotic encapsulation further limit adjunctive use of antimetabolites. These results have sparked investigations into safer, more effective agents to improve survivability of GDDs.

A dynamic homeostasis of the extracellular matrix is maintained by biochemical and biophysical signaling. Disruption of this homeostasis, as in the case of injury, leads to wound healing and promotion of the fibrotic pathway. Molecular signaling, predominantly transformation growth factor $\beta$ (TGF- $\beta$ ), drives transdifferentiation of fibroblasts into myofibroblasts [11]. Myofibroblasts subsequently upregulate $\alpha$ smooth muscle actin (SMA) fibers as well as various integrins and growth factors that are responsible for deposition of a dense fibrotic collagen capsule [12]. Several studies have explored agents targeting specific molecules in the fibrosis cascade. Inhibition of TGF- $\beta$ showed promise in animal models, but a clinical study found that a monoclonal antibody (CAT-152) was not effective at preventing trabeculectomy failure [13]. Preliminary studies investigating anti-transforming growth factor $\beta 2$ (anti-TGF$\beta 2)$, anti-vascular endothelial growth factor (anti-VEGF), anti-placental growth factor (antiPIGF), inhibitors of platelet collagen interaction (saratin), and application of amniotic 
membrane have all shown success, but have not expanded to clinical trials [14-18].

Medical device coatings have emerged as a feasible biochemical solution to prevent adverse reactions at and around foreign implant sites. Increasingly, coatings that are anti-thrombogenic, hydrophilic, and drug-eluting are being utilized in vascular surgery. Specifically, hydrophilic coatings are used in endovascular catheters to improve mobility, prevent friction, and abate particulate formation in hopes of reducing an inflammatory response [19]. Several studies have shown heparin to inhibit early inflammatory signaling by blocking the aforementioned chemokines, integrins, growth factors, and receptors [20]. These techniques, including heparin-coated intraocular lenses and slow-release antimetabolite-coated GDDs, have been studied for ophthalmic use to reduce postoperative inflammation [21-25].

Beyond chemical factors, mechanical force on the extracellular matrix is a major factor in the fibroproliferative process. Mechanical tension acts through transmembrane integrins to free sequestered TGF- $\beta$ which promotes and maintains a myofibroblast response [26]. Myofibroblast wound contractility induces more tension, leading to positive feedback and dense scar formation [27]. Medical devices with a micro-patterned geometric surface mimic the extracellular matrix, and laser patterning of medical device surfaces may help create an antiproliferative effect.

Studies of healing ligaments and tendons show the collagen matrix is not aligned as it is in normal tissues [28]. Micro-patterned surfaces act as mechanical guidance cues, influencing cellular orientation, morphology, and migration during scar formation [29-31]. Studies of post-infarct myocardial scar formation have shown mechanical guidance cues were the most important determinant in collagen alignment to generate anisotropic scar tissue which more closely resembles uninjured tissue [32].

Based on these observations, modified Ahmed glaucoma valves (AGVs, New World Medical, Rancho Cucamonga, CA, USA) were constructed with different medical device coatings in an attempt to reduce fibrotic encapsulation and lower outflow resistance. Modified valves included a hydrophilic plate coating, a heparin plate coating, and AGV with a proprietary micro-patterned plate surface. In this study, we compared the outflow resistance of the AGV (control) to that of the aforementioned modified AGVs in a rabbit model. Additionally, we compared the histologic appearance of the capsules surrounding the modified implants to those of the standard AGV.

\section{METHODS}

\section{Study Design}

All procedures were performed in accordance with the Association for Research in Vision and Ophthalmology Statement for the Use of Animals in Ophthalmic and Vision Research and with the approval of the University of Colorado Anschutz Medical Campus Institutional Animal Care and Use Committee (IACUC). Both eyes of 12 New Zealand white rabbits $(n=24)$ were divided into four equal groups that underwent surgical implantation of AGVs in both eyes. The groups included commercially available AGV (control, $n=3$ rabbits, 6 eyes), AGV with hydrophilic plate coating ( $n=3$ rabbits, 6 eyes), AGV with heparin plate coating $(n=3$ rabbits, 6 eyes), and AGV with a micro-patterned plate surface ( $n=3$ rabbits, 6 eyes). The number of rabbits was chosen based on our previous studies with a similar animal model [33]. One image stained with hematoxylin and eosin from the micro-patterned plate group was lost due to damaged tissue and was excluded in analysis. Both eyes of rabbits 1, 2, 4, and 10 were excluded in perfusion analysis due to unrecordable pressures during testing. As such, the groups included a commercially available AGV (control, $n=1$ rabbits, 1 eyes), AGV with hydrophilic plate coating ( $n=2$ rabbits, 2 eyes), AGV with heparin plate coating $(n=3$ rabbits, 3 eyes), and AGV with a micro-patterned plate surface ( $n=2$ rabbits, 2 eyes). There were no measurable variations in height, width, or length of the experimental plates when compared to the control AGV. All surgeries were 


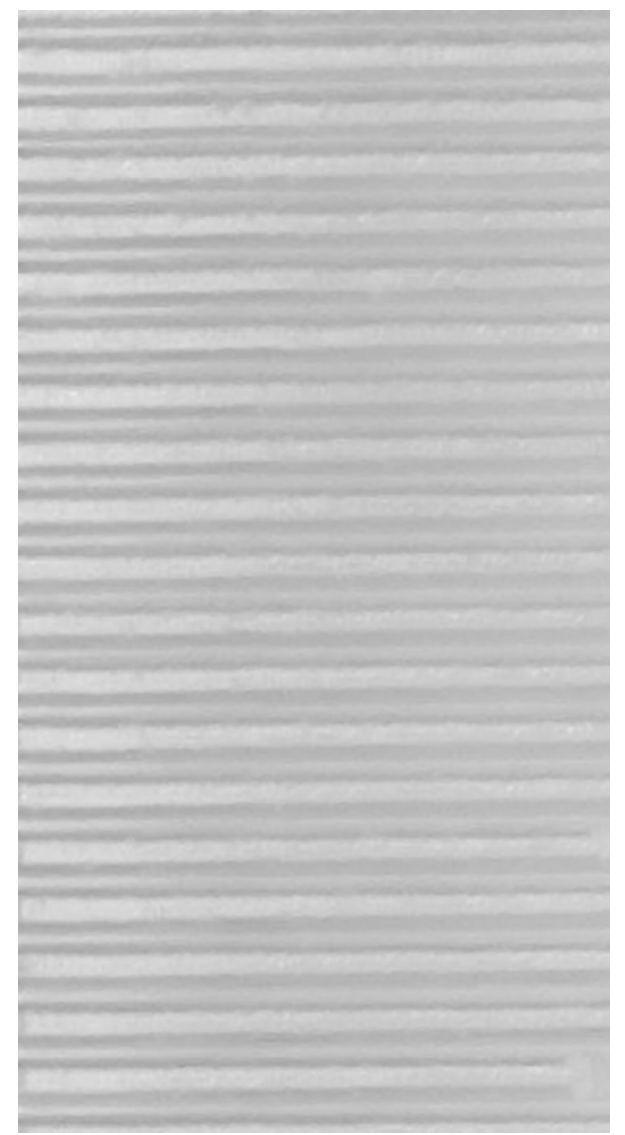

Fig. 1 Depiction of surface modifications for the plate surface micro-pattern AGV (×150 magnification)

performed by a single surgeon (J.R.S.) experienced in animal-based ophthalmic surgery.

\section{Prototype Design}

The control implant was an AGV Model FP7 consisting of a silicone plate and tube. Experimental implants were as follows: AGV FP7 with hydrophilic plate coating, AGV FP7 with heparin plate coating, and AGV FP7 with a micropatterned plate surface (Fig. 1).

\section{Glaucoma Filtering Surgery Technique}

The surgery was performed as described in previous studies [34-36]. Briefly, rabbits were anesthetized using a combination of intramuscular ketamine hydrochloride and xylazine (25-35 mg/kg ketamine and $5 \mathrm{mg} / \mathrm{kg}$ xylazine).
Each eye was prepared with povidone-iodine (betadine; Purdue Pharma LP, Stamford, CN, USA) followed by a saline rinse, and local anesthesia was accomplished with injection of $2 \%$ lidocaine at the surgical site. A 7-0 polyglactin 910 (Vicryl; Ethicon, Somerville, NJ, USA) traction suture was passed through the supratemporal limbus to rotate the eye downward. A fornix-based conjunctival dissection was completed in the supratemporal quadrant followed by further posterior dissection between the superior and lateral muscles. The AGV was brought to the operative site and primed with a 27-gauge needle and balanced salt solution. The end plate was tucked into the dissected supratemporal quadrant and secured to the underlying scleral bed with two interrupted 10-0 nylon sutures (Ethicon, Somerville, NJ, USA) approximately $7 \mathrm{~mm}$ from the limbus. The silicone tube was cut $0.5 \mathrm{~mm}$ anterior to the limbus with Westcott scissors. A 23-gauge butterfly needle was used to enter the anterior chamber $0.25 \mathrm{~mm}$ posterior to the limbus, and $0.1 \mathrm{~mL}$ of viscoelastic (Healon; Advanced Medical Optics, Inc., Santa Ana, CA, USA) was injected. The silicone tube was inserted into the anterior chamber through the needle tract and secured to the surrounding sclera with a 10-0 nylon suture. The conjunctiva was secured to the limbus with an interrupted 10-0 polyglactin 910 suture. The same surgeon (J.R.S.) performed all the surgeries in this study.

\section{Baseline Measurements and Postoperative Evaluation}

All rabbits were examined on postoperative day 1 as well as weekly until the study end date. In all eyes, topical moxifloxacin $0.5 \%$ solution $\left(\right.$ Vigamox $^{\circledR}$; Alcon, Fort Worth, TX, USA) and prednisolone acetate 1\% suspension (Predforte $^{\circledR}$; Allergan, Irvine, CA, USA) were each instilled four times per day for 7 days following surgery.

Rabbits were assessed by slit lamp for anterior chamber depth and tube placement, presence of conjunctival hyperemia, subconjunctival hemorrhage, implant body or tube extrusion, suture exposure, discharge, 
infection, corneal edema or epithelial defects, quality of red reflex, and any other complications. Intraocular pressure was not collected as an endpoint since our specific metrics of interest were histologic and perfusion pressure differences between groups.

\section{Perfusion Testing}

At the end of 6 weeks, all rabbits were anesthetized and sedated. A corneal flap was made in the left eye of each rabbit to retrieve the proximal portion of the tube which was cannulated with a 27-gauge cannula attached to the perfusion system. A flow rate of $2.5 \mathrm{ml} / \mathrm{min}$ was infused into the implant, and hydrostatic pressure readings were recorded by a standalone perfusion system until a steady-state pressure was achieved. Steady state was defined as an average of the last 2000 measurements. Hydrostatic pressure was recorded every $0.09 \mathrm{~s}$ for approximately 6008 measurements per perfusion test on each eye. Conversion to the International System of Units (SI) was performed, and outflow resistance was calculated using Ohm's law (Pressure $=$ Flow $\times$ Resistance) .

\section{Histology}

Immediately after perfusion testing was completed, each animal was euthanized. All eyes were enucleated and immediately immersed in a mixture of $5 \%$ paraformaldehyde and $2.5 \%$ neutral buffered formalin for $24 \mathrm{~h}$. The relevant anterior quadrant of each globe was dehydrated, embedded in paraffin, and sent for microtome sectioning. Sagittal sections of each eye (3.5-5.0 $\mu \mathrm{m}$ thick) were prepared for each of the following: (1) hematoxylin and eosin (H\&E, Sigma-Aldrich, St. Louis, MO, USA), (2) Masson trichrome (Sigma-Aldrich, St. Louis, MO, USA), and (3) immunohistochemical (ICH) staining using a mouse monoclonal antibody for $\alpha$ smooth muscle actin (SMA; Sigma-Aldrich, St. Louis, MO, USA). Sections were photographed using a Nikon Eclipse 80i microscope (Melville, NY, USA) equipped with a 5-megapixel D5Fi1 color camera and either $\times 4$ or $\times 20$ Plan Fluor objective lenses. Overview images of each microtome section were taken at $\times 30$ and five additional $\times 200$ images were taken $500 \mu \mathrm{m}$ apart from the center along the conjunctival ridge of implant. The five images of each microtome section were used to represent the fibrosis determined by each stain in one eye. Thirty $(n=30)$ images were analyzed per stain per experimental group (five images for each of the two eyes in each experimental group consisting of three rabbits). Image analysis was performed using the NIS-Elements software package (Nikon, Melville, NY, USA). The edge of fibrosis was measured from the inner edge of the bleb to the transition point at the conjunctival interface. For H\&E and trichrome staining, the transition point was determined to be at the boundary of tightly bound collagen fibers and loosely organized collagen fibers. For SMA stain, the transition point was determined to be when the brown ICH stain faded to the background.

\section{Statistical Analysis}

Each eye $(n=24)$ was treated as an independent observation. All statistical analyses were performed using SAS software (version 9.2, SAS Institute Inc., Cary, NC, USA) in consultation with an epidemiologist (JP).

Perfusion Analysis: The three GDD treatment groups were compared to controls with generalized linear modeling to investigate the association of treatment group on the outcome of perfusion hydrostatic pressure. The model accounted for intra-subject correlation of multiple measurements per subject at multiple time intervals and the potential of interaction between treatment group and time. A $p$ value of $<0.05$ was considered statistically significant.

Histology Analysis: Descriptive statistics including mean, median, and standard deviation were calculated. The three GDD treatment groups were compared to controls with generalized linear modeling to investigate the association of stain, treatment group, and fibrosis. The model accounted for intra-subject correlation of 15 measurements of fibrosis per eye and the interaction between treatment group and stain. Differences in net fibrosis between 
Table 1 Hydrostatic pressure and resistance after perfusion testing of control and modified implants

\begin{tabular}{|c|c|c|c|c|c|c|}
\hline $\begin{array}{l}\text { Description of } \\
\text { implant (number } \\
\text { of observations) }\end{array}$ & $\begin{array}{l}\text { Number of } \\
\text { total } \\
\text { measurements }\end{array}$ & $\begin{array}{l}\text { Average hydrostatic } \\
\text { pressure at steady } \\
\text { state }(\mathbf{m m ~} \mathbf{H g})\end{array}$ & $\begin{array}{l}\text { Difference } \\
\text { from control } \\
(\mathrm{mm} \mathrm{Hg})\end{array}$ & $p$ value & $\begin{array}{l}\text { Standard } \\
\text { error }\end{array}$ & $\begin{array}{l}\text { Resistance } \\
\left(\frac{\frac{N}{m^{2}}}{\frac{m^{3}}{\text { second }}} \times 10^{13}\right)\end{array}$ \\
\hline Control $(n=1)$ & 6008 & 34.6 & - & & - & 11.1 \\
\hline $\begin{array}{l}\text { Hydrophilic plate } \\
\text { coating }(n=2)\end{array}$ & 12,016 & 25.0 & -9.6 & $<0.001$ & 1.3 & 8.0 \\
\hline $\begin{array}{l}\text { Heparin plate } \\
\quad \text { coating }(n=3)\end{array}$ & 18,024 & 30.2 & -4.4 & $<0.001$ & 2.3 & 9.6 \\
\hline $\begin{array}{l}\text { Micro-patterned } \\
\text { surface }(n=2)\end{array}$ & 12,016 & 16.0 & -18.6 & $<0.001$ & 4.0 & 5.1 \\
\hline
\end{tabular}

treatment groups were compared with the Friedman test. A $p$ value of $<0.05$ was considered statistically significant.

\section{RESULTS}

\section{Perfusion Testing}

Hydrostatic pressures during perfusion studies are shown in Table 1 and showed significant group differences in the control AGV versus AGV with hydrophilic plate coating (mean difference $-9.59 \mathrm{~mm} \mathrm{Hg} ; p<0.001)$, AGV with heparin plate coating (mean difference $-4.43 \mathrm{~mm} \mathrm{Hg} ; p<0.001$ ), and AGV with a plate surface micro-pattern (mean difference $-18.61 \mathrm{~mm} \mathrm{Hg}, p<0.001)$. The control AGV showed the most resistance to flow, followed by the AGV with heparin plate coating, AGV with hydrophilic plate coating, and AGV with plate surface micro-pattern, respectively.

\section{Histology}

Histologically, a thin capsule consisting of fibroblast and myofibroblast proliferation with intercellular collagen was present around all implants (Figs. 2, 3, 4), visualized as either a densely stained eosin (pink) or trichrome (blue) structure. Table 2 summarizes the mean fibrosis, mean difference, and range for each group and each staining technique. When all stains are averaged, the control had the most fibrosis $(90.4 \mu \mathrm{m})$, followed by the hydrophilic plate coating $(84.2 \mu \mathrm{m}$; mean difference $-6.2 \mu \mathrm{m}$, $p=0.425)$, plate surface micro-pattern $(63.7 \mu \mathrm{m} ; \quad$ mean difference $-26.7 \mu \mathrm{m}$, $p=0.003)$, and heparin plate coating $(49.3 \mu \mathrm{m}$; mean difference $-41.1 \mu \mathrm{m}, p=0.006$ ), respectively. Both the heparin plate coating and plate surface micro-pattern had significantly less fibrosis compared to the control on H\&E and trichrome stain (Table 2). Only the AGV with heparin plate coating showed significantly less fibrosis on SMA staining compared to the control (mean difference $-26.2 \mu \mathrm{m}, p=0.033$ ). There were no episodes of endophthalmitis, corneal epithelial toxicity, or persistent inflammation in all 24 treated eyes.

\section{DISCUSSION}

Scar formation and fibrosis remains a common cause for surgical failure in GDD implantation [2-5]. An ideal GDD would consist of an inert substance with no inflammatory response and have a significant and predictable reduction in IOP. The AGV utilizes a valve system to help prevent post-operative complications such as hypotony, but IOP lowering can be limited by postoperative fibrosis. Antimetabolites such as MMC and 5-FU are used during trabeculectomy to limit the fibrotic response, but have not been 


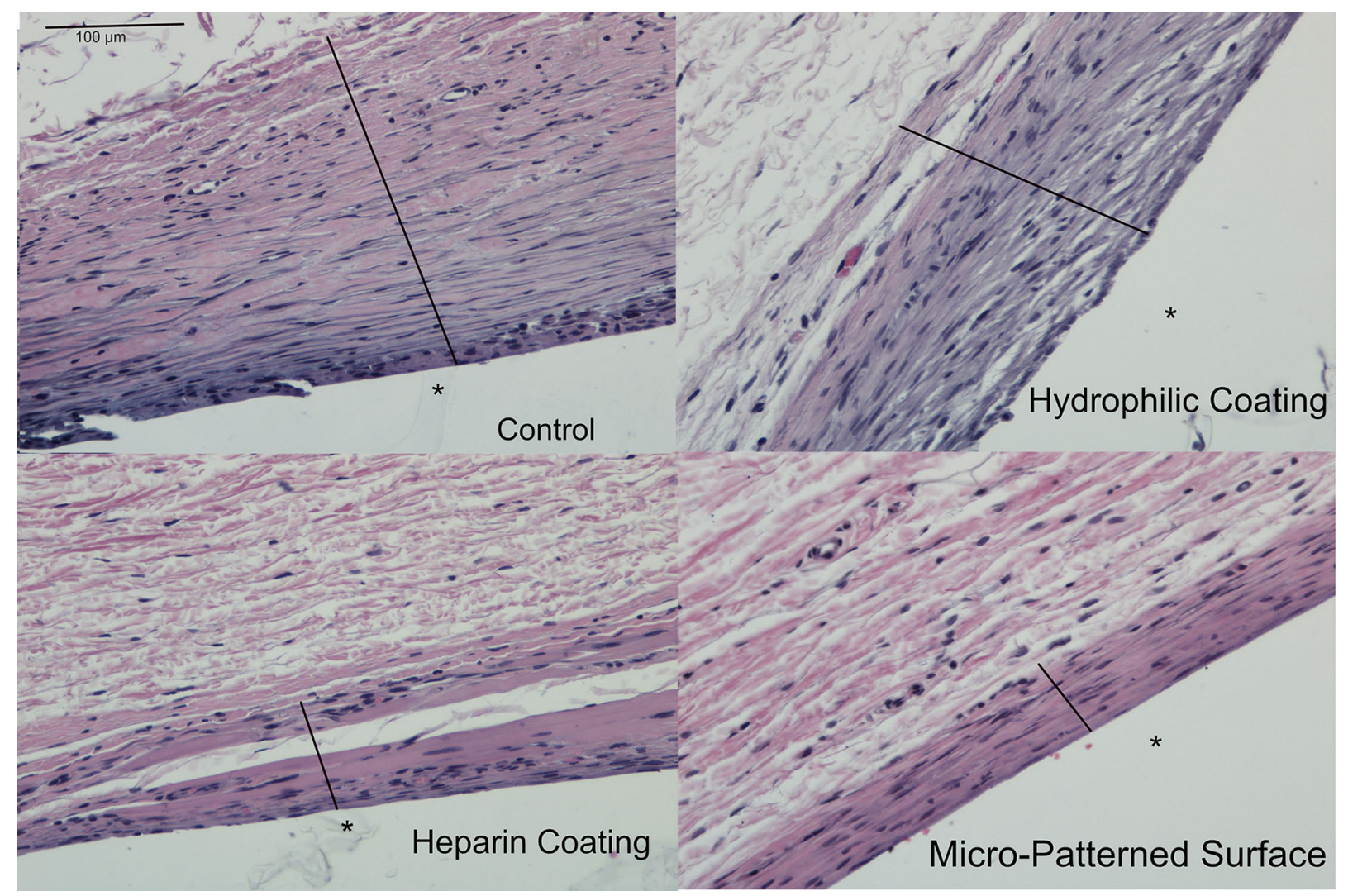

Fig. 2 Histologic analysis of bleb tissue revealed significantly less collagen deposition with the heparin coating and micro-patterned surface AGV when compared to the control on hematoxylin and eosin stain. The fibrous

shown to be as beneficial during GDD implantation.

Recent efforts have focused on targeted molecular therapies in hopes of preventing fibrosis while decreasing adverse effects associated with antimetabolite use. Studies of antiVEGF, anti-TGF- $\beta$, anti-PIGF, and application of amniotic membranes indicate preliminary success, but have not broadened to clinical use [13-18]. Fields such as vascular surgery have elucidated the role of medical device coatings, but the technology has not yet expanded into ophthalmic clinical practice. To our knowledge, this is the first study exploring the use of hydrophilic and heparin plate coatings as well as a micro-patterned plate surface in hopes of reducing postoperative fibrosis and resistance to outflow. capsule in the roof of the bleb associated with heparin was looser, with more disorganized collagen structure; *bleb cavity, ( $\times 200$ magnification)

In order to analyze the results of the study, it is best to consider both perfusion and histologic results simultaneously. Perfusion testing has been previously used to gauge the filtering capacity of capsules around GDDs [37]. This study demonstrates that all modified AGVs had significantly reduced outflow resistance in a rabbit perfusion model. Overall, the micro-patterned surface had the least outflow resistance with relatively little fibrosis on histology. The physical environment in the post-operative period likely plays a significant role in wound healing and the fibrotic response. Microscopic patterned surfaces mimic the extracellular environment; this physical sequestration of stored TGF- $\beta$ and mechanical reduction of tension may prevent the transdifferentiation of fibroblasts into myofibroblasts. 


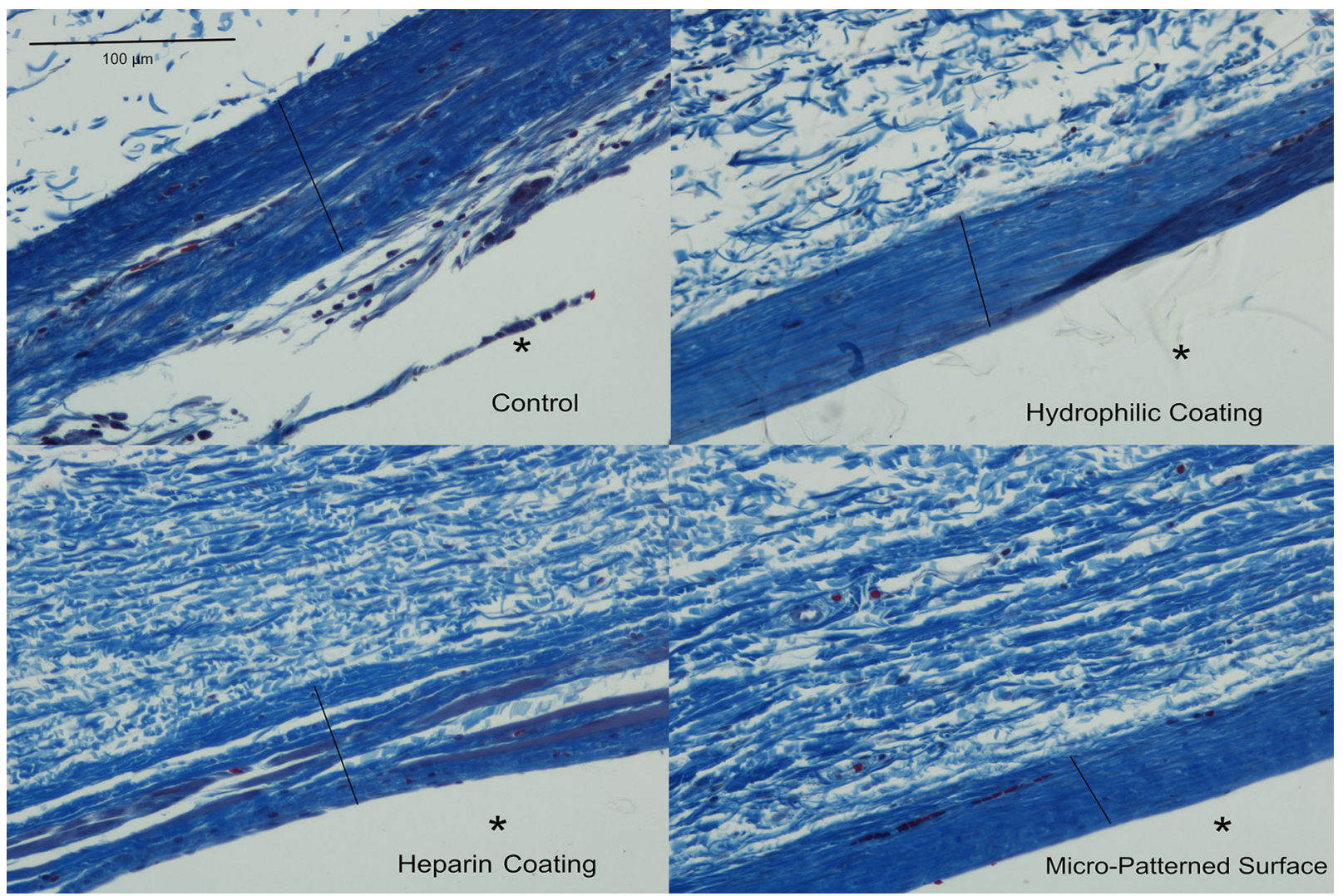

Fig. 3 Histologic analysis of bleb tissue revealed significantly less fibrous tissue with heparin-coated and micropatterned surface AGVs when compared to the control on Masson trichrome stain. The fibrous capsule in the roof of

There has been an emergence of research into the non-coagulant use of heparin for various inflammatory disease states such as pulmonary fibrosis, cystic fibrosis, rheumatoid arthritis, and wound healing $[20,38]$. Beyond its role in the coagulation cascade, heparin has been shown to bind and inhibit various mediators of the inflammatory and scar-formation cascade, notably chemokines, complement, integrins, and angiogenic and growth factors [20, 39]. The current study suggests these anti-inflammatory properties profoundly reduce scar formation and aqueous outflow resistance.

While the AGV modified with a hydrophilic plate coating significantly reduced outflow resistance compared to both the control and the bleb associated with heparin was looser, with more disorganized collagen structure; *bleb cavity, $(\times 200$ magnification)

heparin plate coating, it showed statistically similar fibrosis when compared to the control. It remains unclear why this discordance between outflow resistance and measured fibrotic encapsulation exists. It is possible the hydrophilic nature of the coating reduces resistance beyond the silicone body of the AGV without impairing the fibrotic response.

Perfusion testing is limited by four subjects recording pressures close to zero throughout the entirely of the study. It is unclear as to why these subjects failed to reach a substantial steady-state pressure with potential mechanisms including failure of the valve to reduce flow or bleb leak. Future studies could consider increasing perfusion flow rates to further increase hydrostatic pressures and reduce the 


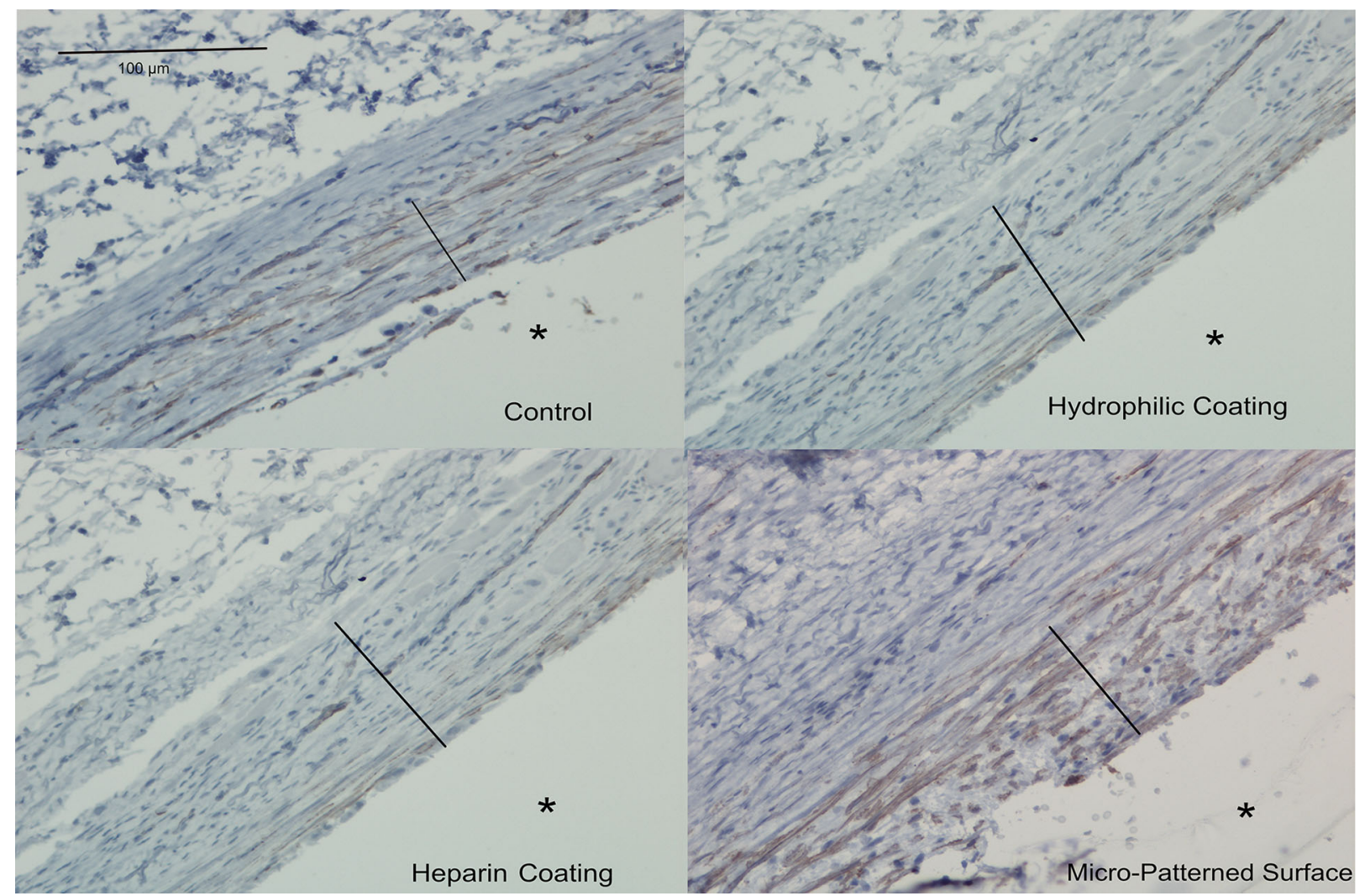

Fig. 4 Immunohistochemical staining for $\alpha$-SMA showed transdifferentiation of fibroblasts into myofibroblasts at the inner surface of the bleb. Expression of $\alpha$-SMA reveals significantly less expression in the heparin coating and statistically similar expression in the hydrophilic and micro-patterned surface when compared to the control AGV; *bleb cavity, (×200 magnification)

compared to a single control in perfusion testing. Although 6 weeks is in line with previous studies investigating fibrotic encapsulation in a rabbit model of glaucoma surgery, the longterm effects of the modified GDDs were not studied. Additionally, diminished postoperative fibrosis and reduced outflow resistance was used as a surrogate for improved drainage device success. It remains to be seen if these results would lead to substantial reduction of IOP and/ or reduction in failure rates. It is also noted that results from an animal study may not be directly applicable to human patients. The New Zealand rabbit is, however, an established model for evaluation of glaucoma surgery $[10,17,18,26]$. subjects from the control were excluded in perfusion analysis. This remains a significant limitation as all experimental groups were 
Table 2 Histologic results after control and modified valve implantation

\begin{tabular}{|c|c|c|c|c|c|c|c|}
\hline & $n$ & $\begin{array}{l}\text { Mean } \\
\text { fibrosis }(\mu \mathrm{m})\end{array}$ & $\begin{array}{l}\text { Mean } \\
\text { difference } \\
(\mu \mathrm{m})\end{array}$ & $\begin{array}{l}\text { Standard } \\
\text { deviation }(\mu \mathrm{m})\end{array}$ & $\begin{array}{l}\text { Median } \\
\text { fibrosis }(\mu \mathrm{m})\end{array}$ & $\begin{array}{l}\text { Range of } \\
\text { values }(\mu \mathrm{m})\end{array}$ & $p$ value \\
\hline \multicolumn{8}{|c|}{ Fibrosis with HङE stain } \\
\hline Control & 30 & 104.0 & - & 76.5 & 87.2 & $25.2-370.5$ & \\
\hline $\begin{array}{l}\text { Hydrophilic } \\
\text { coating }\end{array}$ & 30 & 82.3 & -21.7 & 35.9 & 74.9 & $30.3-195.9$ & 0.077 \\
\hline $\begin{array}{l}\text { Heparin } \\
\text { coating }\end{array}$ & 30 & 57.6 & -46.4 & 32.3 & 54.2 & $16.1-178.3$ & 0.002 \\
\hline $\begin{array}{l}\text { Micro- } \\
\text { patterned } \\
\text { surface }\end{array}$ & 29 & 71.4 & -32.6 & 20.9 & 68.9 & $39.8-130.9$ & 0.009 \\
\hline \multicolumn{8}{|c|}{ Total mean fibrosis $=78.9(\mu \mathrm{m})$} \\
\hline \multicolumn{8}{|c|}{ Fibrosis with trichrome stain } \\
\hline Control & 30 & 82.1 & - & 40.2 & 73.7 & $21.5-217.3$ & \\
\hline $\begin{array}{l}\text { Hydrophilic } \\
\text { coating }\end{array}$ & 30 & 85.1 & 3.0 & 46.7 & 79.0 & $18.6-211.4$ & 0.807 \\
\hline $\begin{array}{r}\text { Heparin } \\
\text { coating }\end{array}$ & 30 & 31.4 & -50.7 & 15.6 & 29.1 & $7.6-70.3$ & $<0.001$ \\
\hline $\begin{array}{l}\text { Micro- } \\
\text { patterned } \\
\text { surface }\end{array}$ & 30 & 53.2 & -28.9 & 22.0 & 50.3 & $21.8-120.1$ & 0.018 \\
\hline \multicolumn{8}{|c|}{ Total mean fibrosis $=62.9(\mu \mathrm{m})$} \\
\hline \multicolumn{8}{|c|}{ Fibrosis with $\alpha$-smooth muscle actin } \\
\hline Control & 30 & 85.1 & - & 71.5 & 76.4 & $17.7-329.8$ & - \\
\hline $\begin{array}{l}\text { Hydrophilic } \\
\text { coating }\end{array}$ & 30 & 85.1 & 0.0 & 44.3 & 75.9 & $28.3-240.0$ & 0.998 \\
\hline $\begin{array}{l}\text { Heparin } \\
\text { coating }\end{array}$ & 30 & 58.9 & -26.2 & 52.8 & 46.6 & $10.8-308.5$ & 0.033 \\
\hline $\begin{array}{l}\text { Micro- } \\
\text { patterned } \\
\text { surface }\end{array}$ & 30 & 66.5 & -18.6 & 56.0 & 38.2 & $14.9-254.5$ & 0.129 \\
\hline \multicolumn{8}{|c|}{ Total mean fibrosis $=73.9(\mu \mathrm{m})$} \\
\hline \multicolumn{8}{|c|}{ Net fibrosis by group } \\
\hline Control & 90 & 90.4 & - & 65.3 & 82.9 & $17.7-370.5$ & - \\
\hline $\begin{array}{l}\text { Hydrophilic } \\
\text { coating }\end{array}$ & 90 & 84.2 & -6.2 & 42.7 & 76.4 & $18.6-240.0$ & 0.425 \\
\hline
\end{tabular}


Table 2 continued

\begin{tabular}{|c|c|c|c|c|c|c|c|}
\hline & $n$ & $\begin{array}{l}\text { Mean } \\
\text { fibrosis }(\mu \mathrm{m})\end{array}$ & $\begin{array}{l}\text { Mean } \\
\text { difference } \\
(\mu \mathrm{m})\end{array}$ & $\begin{array}{l}\text { Standard } \\
\text { deviation }(\mu \mathrm{m})\end{array}$ & $\begin{array}{l}\text { Median } \\
\text { fibrosis }(\mu \mathrm{m})\end{array}$ & $\begin{array}{l}\text { Range of } \\
\text { values }(\mu \mathrm{m})\end{array}$ & $p$ value \\
\hline $\begin{array}{l}\text { Heparin } \\
\text { coating }\end{array}$ & 90 & 49.3 & -41.1 & 38.9 & 42.0 & $7.56-308.5$ & 0.006 \\
\hline $\begin{array}{l}\text { Micro- } \\
\text { patterned } \\
\text { surface }\end{array}$ & 89 & 63.7 & -26.7 & 37.9 & 56.0 & $14.9-254.5$ & 0.003 \\
\hline \multicolumn{8}{|c|}{ Total mean fibrosis of all samples $=73.1(\mu \mathrm{m})$} \\
\hline
\end{tabular}

One image was lost from the micro-patterned surface due to damaged tissue and therefore was excluded from analysis

\section{CONCLUSION}

The results of this preliminary study suggest a role for a modified AGV, such as a device with a micro-patterned plate surface and heparin plate coating, as a technique to reduce postoperative fibrosis following GDD surgery. The micro-patterned plate surface and heparin plate coating showed significantly less fibrosis and less outflow resistance than the control. Although the AGV with a hydrophilic plate coating outperformed the control in reducing outflow resistance, it failed to have a significantly different degree of fibrosis compared to the control. Further studies are needed to better characterize the safety and results of this preliminary study.

\section{ACKNOWLEDGEMENTS}

We would like to acknowledge Patricia Lenhart for her work on preparing histological sections.

Funding. We would like to acknowledge Research to Prevent Blindness for supporting our study by providing a challenge grant to the Department of Ophthalmology at the University of Colorado. We acknowledge New World Medical for providing an unrestricted educational grant and for supplying the devices used for the study. No funding or sponsorship was received for the publication of this article.

Authorship. All named authors meet the International Committee of Medical Journal Editors (ICMJE) criteria for authorship for this article, take responsibility for the integrity of the work as a whole, and have given their approval for this version to be published.

Disclosures. Nathan Fischer, David Ammar, Jennifer Patnaik, and Jeffrey SooHoo have no conflicts of interest. Suhail Abdullah and Eric Porteous are employees of New World Medical. Malik Kahook declares that he receives patent royalties from New World Medical for devices unrelated to those in the current study. He is also a consultant to New World Medical.

Compliance with Ethics Guidelines. All procedures were performed in accordance with The Association for Research in Vision and Ophthalmology Statement for the Use of Animals in Ophthalmic and Vision Research and with approval of the University of Colorado Anschutz Medical Campus Institutional Animal Care and Use Committee (IACUC).

Data Availability. The datasets generated during and/or analyzed during the current study are not publicly available due to the proprietary nature of the device coatings, but are 
available from the corresponding author on reasonable request.

Open Access. This article is licensed under a Creative Commons Attribution-NonCommercial 4.0 International License, which permits any non-commercial use, sharing, adaptation, distribution and reproduction in any medium or format, as long as you give appropriate credit to the original author(s) and the source, provide a link to the Creative Commons licence, and indicate if changes were made. The images or other third party material in this article are included in the article's Creative Commons licence, unless indicated otherwise in a credit line to the material. If material is not included in the article's Creative Commons licence and your intended use is not permitted by statutory regulation or exceeds the permitted use, you will need to obtain permission directly from the copyright holder. To view a copy of this licence, visit http://creativecommons.org/licenses/by$\mathrm{nc} / 4.0 /$.

\section{REFERENCES}

1. Cook C, Foster P. Epidemiology of glaucoma: what's new? Can J Ophthalmol. 2012;47:223-6.

2. Gedde SJ, Schiffman JC, Feuer WJ, et al. Treatment outcomes in the tube versus trabeculectomy (TVT) study after 5 years of follow-up. Am J Ophthalmol. 2012;153:789-803.

3. Sharkawy AA, Klitzman B, Truskey GA, et al. Engineering the tissue which encapsulates subcutaneous implants. I. Diffusion properties. J Biomed Mater Res. 1997;37:401-12.

4. Mahale A, Othman MW, Al Shahwan S, et al. Altered expression of fibrosis genes in capsules of failed Ahmed glaucoma valve implants. PLoS One. 2015;10:E0122409.

5. Thieme HB, Choritz L, Hofmann-Rummelt C, et al. Histopathologic findings in early encapsulated blebs of young patients treated with the Ahmed glaucoma valve. J Glaucoma. 2011;20:246-51.

6. The Fluorouracil Filtering Surgery Study Group. Five-year follow-up of the fluorouracil filtering surgery study. Am J Ophthalmol. 1996;121:349-66.
7. Cohen JS, Greff LJ, Novack GD, et al. A placebocontrolled, double-masked evaluation of mitomycin $\mathrm{C}$ in combined glaucoma and cataract procedures. Ophthalmology. 1996;103:1934-42.

8. Lama PJ, Fechtner RD. Antifibrotics and wound healing in glaucoma surgery. Surv Ophthalmol. 2003;48:314-46.

9. Costa VP, Azuara-Blanco A, Netland PA, et al. Efficacy and safety of adjunctive mitomycin $\mathrm{C}$ during Ahmed glaucoma valve implantation: a prospective randomized clinical trial. Ophthalmology. 2004;111:1071-6.

10. Prata JA Jr, Minckler DS, Mermoud A, et al. Effects of intraoperative mitomycin-C on the function of Baerveldt glaucoma drainage implants in rabbits. J Glaucoma. 1996;5:29-38.

11. Hinz B, Mastrangelo D, Iselin CE, et al. Mechanical tension controls granulation tissue contractile activity and myofibroblast differentiation. Am J Pathol. 2001;159:1009-20.

12. Tomasek JJ, Gabbiani G, Hinz B, et al. Myofibroblasts and mechanoregulation of connective tissue remodelling. Nat Rev Mol Cell Biol. 2002;3:349-63.

13. CAT-152 0102 Trabeculectomy Study Group, 161, Khaw P, Grehn F, Holló G, et al. A phase III study of sub- conjunctival human anti-transforming growth factor beta (2) monoclonal antibody (CAT-152) to prevent scarring after first-time trabeculectomy. Ophthalmology. 2007;114:1822-30.

14. Van Bergen T, Hollanders K, Sijnave D, et al. Bevacizumab together with MMC may have complementary effects in the improvement of surgical outcome after glaucoma filtration surgery. Invest Ophthalmol Vis Sci. 2013;54:4774.

15. Cordeiro M, Gay J, Khaw P. Human anti-transforming growth factor-beta2 antibody: a new glaucoma anti-scarring agent. Invest Ophthalmol Vis Sci. 1999;40:2225-34.

16. Van Bergen T, Jonckx B, Hollanders K, et al. Inhibition of placental growth factor improves surgical outcome of glaucoma surgery. J Cell Mol Med. 2013;17:1632-43.

17. Min J, Lukowski Z, Levine M, et al. Prevention of ocular scarring post glaucoma filtration surgery using the inflammatory cell and platelet binding modulator saratin in a rabbit model. PLoS One. 2012;7:E35627.

18. Lee JW, Park WY, Kim EA, et al. Tissue response to implanted Ahmed glaucoma valve with adjunctive amniotic membrane in rabbit eyes. Ophthalmic Res. 2014;51:129-39. 
19. Niemczyk A, El Fray M, Franklin SE. Friction behaviour of hydrophilic lubricious coatings for medical device applications. Tribol Int. 2015;89:54-61.

20. Cassinelli G, Naggi A. Old and new applications of non-anticoagulant heparin. Int J Cardiol. 2016;212: S14-21.

21. Lin CL, Wang AG, Chou JCK, et al. Heparin-surfacemodified intraocular lens implantation in patients with glaucoma, diabetes, or uveitis. J Cataract Refract Surg. 1994;20:550-3.

22. Trocme SD, Li H. Effect of heparin-surface-modified intraocular lenses on postoperative inflammation after phacoemulsification; a randomized trial in a United States patient population. Ophthalmology. 2000;107:1031-7.

23. Maedel S, Hirnschall N, Chen YA, et al. Effect of heparin coating of a foldable intraocular lens on inflammation and capsular bag performance after cataract surgery. J Cataract Refract Surg. 2013;39: $1810-7$.

24. Jacob JT, Lacour OJ, Burgoyne CF. Slow release of the antimetabolite 5-fluorouracil (5-FU) from modified Baerveldt glaucoma drains to prolong drain function. Biomaterials. 2001;22:3329-35.

25. Ponnusamy TT, Yu HS, John VA, et al. A novel antiproliferative drug coating for glaucoma drainage devices. J Glaucoma. 2014;23:526-34.

26. Xue M, Jackson C. Extracellular matrix reorganization during wound healing and its impact on abnormal scarring. Adv Would Care. 2015;4: 119-36.

27. Duscher D, Maan ZN, Wong VW, et al. Mechanotransduction and fibrosis. J Biomech. 2014;47: 1997-2005.

28. Wang JH, Jia F, Gilbert TW, et al. Cell orientation determines the alignment of cell-produced collagenous matrix. J Biomech. 2003;36(1):97-102.

29. Gamboa JR, Mohandes S, Tran PL, et al. Linear fibroblast alignment on sinusoidal wave micropatterns. Colloids Surf B Biointerfaces. 2013;104: 318-25.
30. Thomopoulos S, Fomovsky G, Holmes J. The development of structural and mechanical anisotropy in fibroblast populated collagen cells. J Biomed Eng. 2005;127(5):742-50.

31. Dickinson RB, Guido S, Tranquillo RT. Biased cell migration of fibroblasts exhibiting contact guidance in oriented collagen gels. Ann Biomed Eng. 1994;22(4):342-56.

32. Rouillard AD, Holmes JW. Mechanical regulation of fibroblast migration and collagen remodelling in healing myocardial infarcts. J Physiol. 2012;590(18):4585-602.

33. SooHoo J, Seibold L, Laing A, et al. Bleb morphology and histology in a rabbit model of glaucoma filtration surgery using Ozurdex ${ }^{\circledR}$ or mitomycin-C. Molecular Vision. 2012;18:714-9.

34. DeCroos FC, Ahmad S, Kondo Y, et al. Expanded polytetrafluoroethylene membrane alters tissue response to implanted Ahmed glaucoma valve. Curr Eye Res. 2009;34(7):562-7.

35. Jung KI, Lee SB, Kim JH, et al. Foreign body reaction in glaucoma drainage implant surgery. Invest Ophthalmol Vis Sci. 2013;54(6):3957-64.

36. Schoenberg ED, Blake DA, Swann FB, et al. Effect of two novel sustained-release drug delivery systems on bleb fibrosis: an in vivo glaucoma drainage device study in a rabbit model. Transl Vis Sci Technol. 2015;4(3):4.

37. Prata João A, Santos RCR, LaBree L, et al. Surface area of glaucoma implants and perfusion flow rates in rabbit eyes. J Glaucoma. 1995;4(4):274-80.

38. Biran R, Pond D. Heparin coatings for improving blood compatibility of medical devices. Adv Drug Deliv Rev. 2017;112:12-23.

39. Fritzsche J, Alban S, Ludwig RJ, et al. The influence of various structural parameters of semisynthetic sulfated polysaccharides on the P-selectin inhibitory capacity. Biochem Pharmacol. 2006;72: 474-85. 